ARTIGO DE REVISÃO

ISSN 1677-5090

(C) 2017 Revista de Ciências Médicas e Biológicas

DOI: http://dx.doi.org/10.9771/cmbio.v16i2.22543

\title{
Células tronco mesenquimais derivadas de tecido adiposo no tratamento de cirrose hepática
}

\author{
Adipose derived mesenchymal stem cells in the treatment of liver cirrhosis
}

\author{
Luma Cardoso Barreto dos Santos ${ }^{1}$, Laíne Oliveira da Silva Sacramento ${ }^{1}$, Jaqueline de Almeida Andrade ${ }^{1}$, \\ Luiz Fernando Quintanilha ${ }^{2 *}$
}

${ }^{1}$ Bacharelado em Biomedicina - UNIFACS; ${ }^{2}$ Doutor em Ciências pela UFRJ e Pós-doutorado em Células Tronco pela

Universidade de Yamaguchi (JP) Professor titular - UNIFACS

\begin{abstract}
Resumo
Introdução: hepatopatias crônicas figuram entre as principais causas de morte no mundo e o transplante hepático permanece como a única alternativa terapêutica curativa disponível. A terapia celular utilizando células tronco tem sido demonstrada como uma alternativa potencial, porém os mecanismos envolvidos na resolução da doença permanecem em debate. Metodologia: trata-se de uma revisão de literatura, na qual foi realizada uma consulta por artigos científicos selecionados através de busca no banco de dados do PubMed e Scielo no período de agosto de 2016 a junho de 2017. Objetivo: este estudo tem como objetivo descrever os mecanismos envolvidos na regeneração/reparo da cirrose hepática através do tratamento com células tronco mesenquimais derivadas do tecido adiposo (AD-MSCs). Resultados e discussão: os estudos utilizando terapia celular apontam como principais mecanismos a fibrinólise, imunomodulação e atividade antioxidante. Com relação a atividade fibrinolítica, o aumento proeminente na expressão de enzimas como MMP2, MMP3 e MMP9 explica a redução da fibrose normalmente observada. A atividade imunomodulatória das ADMSCs parece estar relacionada com a secreção de agentes imunossupressores e fatores que promovem a hematopoiese. Finalmente, as AD-MSCS são capazes de aumentar a atividade do NF-E2-related fator (Nrf2), um fator de transcrição crucial na expressão de diversas enzimas relacionadas à resolução do estresse oxidativo. Conclusão: os estudos utilizando a terapia celular evidenciaram que fibrinólise, imunomodulação e efeito antioxidante podem, de forma associada, contribuir para os bons resultados apresentados. Apesar dos principais mecanismos propostos terem sido apresentados neste presente trabalho, mais estudos são necessários a fim de determinar a precisa contribuição de cada um deles.

Palavras-chave: Transplante de Células Tronco Mesenquimais. Tecido adiposo. Cirrose hepatica. Antioxidantes. Fibrinólise. Imunomodulação.
\end{abstract}

\begin{abstract}
Introduction: chronic liver diseases are among the leading causes of death in the world and liver transplantation remains the only curative alternative available. Cell therapy using stem cells has been demonstrated as a potential alternative, but the mechanisms involved in this proccess remain unclear. Methodology: we performed a review of the literature, in which a query was made for scientific articles selected through a search in the PubMed and Scielo database from August 2016 to June 2017. Objectives: this study aims to describe the mechanisms involved in the regeneration/repair of liver cirrhosis by treatment with adipose tissue-derived mesenchymal stem cells (AT-MSCS). Results and discussion: studies using cellular therapy point out as main mechanisms fibrinolysis, immunomodulation and antioxidant activity. With regard to fibrinolytic activity, the prominent increase in the expression of enzymes such as MMP2, MMP3 and MMP9 explains the reduction in fibrosis normally observed. The immunomodulatory activity of AT-MSCS appears to be related to the secretion of immunosuppressive agents and factors that promote hematopoiesis. Finally, AT-MSCS are able to increase the activity of the NF-E2-related factor (Nrf2), a crucial transcription factor in the expression of several enzymes related to the resolution of oxidative stress. Conclusion: studies using cell therapy have shown that fibrinolysis, immunomodulation and antioxidant effect may, in an associated way, contribute to the good results presented. Although the main proposed mechanisms have been presented in this present study, more studies are necessary in order to determine the precise contribution of each of them. Keywords: Mesenchymal Stem Cell Transplantation. Adipose Tissue. Hepatic cirrhosis. Antioxidants. Fibrinolysis. Immunomodulation.
\end{abstract}

\section{INTRODUÇÃO}

A cirrose hepática é o principal desfecho esperado em pacientes com doença crônica do fígado. $O$ abuso de álcool e infecção pelos vírus das hepatites B e C representa a maioria dos casos de hepatopatias crônicas em todo o

Correspondente/Corresponding: *Luiz Fernando Quintanilha - Endereço: Av. Luís Viana Filho 3146. Paralela, Salvador - Bahia. CEP. 41.720-200 - Tel: (71) 99696-7808 -E-mail: luiz.mesquita@pro.unifacs.br mundo (D'AMICO et al., 2006; VOLAREVIC et al., 2014). A doença se caracteriza pela fibrose do parênquima do fígado com perda das funções normais do órgão. A formação da fibrose se dá por um acúmulo excessivo de matriz extracelular com formação de cicatrizes que envolvem as áreas lesionadas, podendo evoluir para um quadro de cirrose, estágio onde a doença é considerada irreversível (OKURA et al., 2015). 
Em 2010, a cirrose hepática foi a responsável por cerca de um milhão de mortes no mundo, o que representa um aumento de 33\% em comparação ao ano de 1990. Dados recentes apontam a cirrose hepática como a 12a maior causa de mortes no mundo. No Brasil, a comparação da prevalência da doença entre 2003 e 2008 revelou um aumento estatisticamente significativo de $27 \%$ dos casos de cirrose hepática no país, levando em consideração que esse aumento tende a acometer principalmente as pessoas entre 50 e 79 anos devido às características de cronicidade da doença (BARROS et al., 2011).

Atualmente, apesar do grande número de doentes, a única terapia realmente eficaz é o transplante do órgão, entretanto este procedimento é de difícil realização devido à escassez de doadores compatíveis, possibilidade de rejeição do órgão, necessidade do uso de medicamentos imunossupressores, questões financeiras e riscos inerentes à própria cirurgia (VOLAREVIC et al., 2014; ZHANG et al., 2013). Neste âmbito, segundo dados da Associação Brasileira de Transplante de Órgãos (ABTO) existem aproximadamente 1.500 pessoas na fila de espera para fazer o transplante de fígado. Em 2014, o número de transplantes realizados foi inferior à demanda implicando em um tempo médio de espera superior a 4 anos no SUS, atrás apenas dos valores relativos ao transplante de rim.

Por esses motivos supracitados, a busca por terapias alternativas curativas ou paliativas é extremamente necessária.

Terapias utilizando células tronco têm mostrado resultados promissores em pacientes que estão em tratamento de doenças hepáticas severas (JORNS et al., 2012; OKURA et al., 2015). As células tronco têm características peculiares, tais como auto-renovação, proliferação e diferenciação em diferentes tipos celulares, que possibilitam a sua utilização no tratamento de diversas doenças (YARAK, 2010).

Em relação às hepatopatias, vários autores têm demonstrado que a utilização de células tronco é capaz de minimizar ou reverter os sinais característicos da doença. Liang (2009) e Yin (2014), por exemplo, verificaram que a infusão de células tronco foi capaz de diminuir os níveis de marcadores de lesão hepática (AST, ALT), além de bilirrubina. Além disso, houve aumento de albumina, demonstrando recuperação de função dos hepatócitos.

Para o tratamento de hepatopatias, as células tronco derivadas de medula óssea (BM-MSC) foram largamente testadas em modelos animais e ensaios clínicos apresentando relativo sucesso (ANDREONE et al., 2015; HALDAR et al., 2016; Ll et al., 2015; MOHAMADNEJAD et al., 2016). No entanto, essas células são de difícil obtenção devido a procedimentos dolorosos e os rendimentos são relativamente baixos (WP, 2015; ZUK, 2010).

As células tronco mesenquimais derivadas do tecido adiposo (AD-MSCs) surgem como uma alternativa para a terapia celular devido ao seu baixo custo e à facilidade de obtenção de um quantitativo mais abundante de células em comparação com as células originadas de outras fontes, por exemplo, medula óssea (FATHI; FARAHZADI,
2016). Além disso, as AD-MSCs podem ser obtidas facilmente através de uma lipoaspiração, um procedimento minimamente invasivo e sem danos para a saúde do paciente (ISHIKAWA et al., 2010).

Outras vantagens das AD-MSCs em relação às células de outras fontes são (1) maior capacidade de proliferação quando comparadas com as BM-MSCs e (2) grande potencial imunomodulatório, apesar de alguns estudos mostrarem algumas limitações (HEIDARI et al., 2013; SHIRATSUKI et al., 2015).

Contribuindo para embasar a utilização das AD-MSCs em doenças hepáticas crônicas, estudos demonstraram que elas possuem uma ampla produção de enzimas fibrinolíticas, que são responsáveis por destruir a matriz extracelular formada no fígado cirrótico.

Outro mecanismo já descrito associado às células tronco mesenquimais é o aumento da atividade do ARE (Elemento de Resposta Antioxidante), que é responsável por ativar a transcrição de enzimas antioxidantes, fazendo com que os efeitos nocivos das ROS (Espécies Reativas de Oxigênio) sejam inibidos.

Apesar dos efeitos benéficos já demonstrados pelo transplante de AD-MSCs em modelos experimentais de fibrose/cirrose hepática, muito ainda se discute acerca dos mecanismos que efetivamente contribuem para os resultados positivos.

Portanto, é importante descrever os principais mecanismos envolvidos na regeneração/reparo da cirrose hepática através do tratamento com AD-MSCs.

\section{METODOLOGIA}

Trata-se de uma revisão qualitativa da literatura baseada nos preceitos propostos no guia PRISMA (Preferred Reporting Items for Systematic Reviews and Meta-Analyses) com adaptações. Foram consultadas as bases Scielo (http://www.scielo.org) e Pubmed (http://www. ncbi.nlm.nih.gov/pubmed). Uma busca manual adicional a partir das referências dos principais artigos selecionados também foi realizada. Utilizamos um recorte temporal de dez anos sem limitações de idiomas. As buscas foram realizadas utilizando os seguintes termos descritores "cirrose", "fibrose" e "células tronco derivadas de tecido adiposo" e suas correspondentes em inglês. Utilizou-se a expressão booleana "AND" a fim de localizar os registros os quais contivessem simultaneamente os descritores desejados. A busca foi realizada independentemente pelos autores deste estudo e foi seguida de um rastreamento baseado nos títulos e resumos dos artigos identificados para determinar se os mesmos comporiam o presente trabalho. Observou-se aspectos como impacto da revista, ano de publicação, com particular atenção aos métodos propostos, as inovações e os resultados alcançados.

\section{RESULTADOS E DISCUSSÃO}

Muitos estudos foram publicados nos últimos anos avaliando os benefícios da terapia celular em doenças 
hepáticas. Uma parte considerável deles utilizou as células tronco do tecido adiposo como fonte terapêutica obtendo, em geral, resultados promissores. Efeitos parácrinos são atualmente aceitos para explicar os benefícios provenientes dessa terapia. Dentre os principais mecanismos postulados pelos autores estão fibrinólise, imunomodulação e atividade antioxidante.

\section{Atividade fibrinolítica}

Um dos mecanismos propostos para a eficiência do tratamento da cirrose hepática é a fibrinólise. Dado que a cirrose hepática se caracteriza pelo acúmulo de matriz extracelular (cicatriz), a degradação deste tecido fibroso poderia permitir a renovação hepática. Neste sentido, Okura et al. testaram os efeitos da infusão de AD-MSCs em camundongos tratados com tetracloreto de carbono $\left(\mathrm{CCl}_{4}\right)$ por seis semanas. Verificou-se diminuição de ALT/ AST, aumento da albumina e redução da fibrose. Testes de ELISA revelaram aumento proeminente na expressão de enzimas fibrinolíticas como MMP2, MMP3 e MMP9, o que explica a redução da quantificação de fibrose avaliada por coloração de picrosírius (sirius red) (OKURA et al., 2015).

Em 2013, Yu et al. testaram a eficiência das AD-MSCs em reduzir fibrogênese in vitro e in vivo. Em testes de co-cultura, análises por citometria de fluxo revelaram indução de apoptose nas células estreladas (HSCs) cultivadas com AD-MSCs em transweel plates. Ensaio de CCK-8 foi utilizado para avaliar proliferação das HSCs e estas apresentaram menores taxas de mitose quando cultivadas com as células tronco. Adicionalmente, houve menor expressão de $\alpha$-SMA nas HSCs mensurada por imuno-citoquímica, o que indica menor ativação destas células que estão diretamente ligadas com a fibrogênese. Em consonância, em um modelo experimental de fibrose hepática essas células foram capazes de diminuir a concentração de hidroxiprolina hepática, além de promover reduções significativas de colágeno III e ácido hialurônico séricos, todos marcadores de fibrose (YU et al., 2013).

Uma outra abordagem terapêutica testada foi a utilização de AD-MSC após pré-tratamento com fatores de crescimento. Um dos principais fatores de crescimento utilizados em cultura é o fator de crescimento do fibroblasto (FGF), um importante mitógeno que já se demonstrou importante no desenvolvimento hepático (ISHIKAWA et al., 2006).

Neste sentido, foi demonstrado através de ensaio imunoenzimático que o transplante de AD-MSCs pré-tratadas com fator de crescimento fibroblástico básico (bFGF) em ratos com lesão hepática, induzida por $\mathrm{CCl}_{4} \mathrm{du}$ rante oito semanas, atenua a fibrose hepática através do aumento da expressão de metaloproteinases (KAMADA et al., 2009). Nesse estudo, foi avaliado a contribuição do pré-tratamento das AD-MSC com bFGF para intensificar as atividades anti-fibrinolíticas. Os autores concluíram que o bFGF, além de elevar os níveis de metaloproteinases, também contribuem para manutenção de níveis baixos de marcadores fibrogênicos, como por exemplo fator de cres- cimento transformante (TGF)- $\beta 1$, colágeno l $\alpha 1$ e inibidor da metaloproteinase tecidual 1 (TIMP1). Além disso, os ratos transplantados com AD-MSC + bFGF apresentaram níveis mais baixos de proteína $\alpha$-SMA quando comparados ao grupo AD-MSC sem pré-tratamento e o grupo controle. Estudo similar realizado por Tang WP também testou AD-MSC pré-tratadas com bFGF e demonstrou que os ratos que receberam infusão de AD-MSC + bFGF apresentaram expressão de $\alpha$-SMA significativamente diminuída quando comparado aos grupos controles (KAMADA et al., 2009; WP, 2015).

Outro importante achado é que as AD-MSCs são capazes de secretar diversos fatores ativos, sendo um deles o fator de crescimento de hepatócitos (HGF) (ISHIKAWA et al., 2010). Este fator, por exemplo, promove a apoptose das células hepáticas estreladas, consideradas pivôs da fibrogênese hepática (KIM et al., 2005)

Um robusto conjunto de evidências apontam, portanto, para o efeito de aumento das MMPs, diminuição das TIMPs e inibição da proliferação e ativação das células estreladas hepáticas.

\section{Efeito anti-inflamatório}

Diversos estudos têm demonstrado que as AD-MSCs possuem atividade imunomodulatória. Visto que na cirrose hepática há o aumento da atividade inflamatória devido às sucessivas agressões que ocorrem no tecido, a utilização dessas células poderia atuar na redução da inflamação nessas condições e contribuir para resolução da doença.

Segundo revisado por Ishikawa, as AD-MSCs secretam diversos fatores ativos, tais como agentes imunossupressores IL-1RA (citocina antiinflamatória), IL-6, IL-8, HGF, NGF, MCP-1, e fatores que promovem a hematopoiese: G-CSF, GM-CSF. Esses fatores podem mediar a função do sistema imune inato e modulam a regeneração hepática in vivo (ISHIKAWA et al., 2010).

Crop e colaboradores demonstraram que em condições inflamatórias a capacidade imunossupressora das AD-MSCs se mostrou extremamente alta (CROP et al., 2010a). Este mesmo grupo, em outro estudo, mostrou que existe ativação e proliferação de células T regulatórias (CROP et al., 2010b).

Em um modelo de hepatite aguda, um estudo de Higashimoto e colaboradores comprovou os efeitos imunomodulatórios das AD-MSCs. Foi verificado redução das células $\mathrm{CD} 11 \mathrm{~b}+$, Gr-1+e F4/80+, marcadores de linhagem mielóide. Além disso, a expressão de TNF- $\alpha$ e IFN- $\gamma$ foram reguladas para baixo nas células TCD4 hepáticas (HIGASHIMOTO et al., 2013).

Corroborando com o supracitado, Seki demonstrou que as células TCD8 + foram encontradas predominantemente em ratos cirróticos do grupo controle. Contudo, quando os ratos foram tratados com AD-MSCs, o número de células TCD4+ aumentou e foi comparado à das células TCD8 +, o que indica que o tratamento com AD-MSCs afeta subpopulações de células T. Uma vez que a ativação dos linfócitos B é largamente dependente das 
células T, a influência de AD-MSCs nos linfócitos T pode indiretamente suprimir a função das células B. Desta forma podemos perceber a influência dessas células no combate à intensa resposta imune presente em hepatopatias (SEKI et al., 2013).

Uma possível aplicação do transplante das AD-MSCS devido aos seus efeitos imunomodulatórios seria a inibição da imuno rejeição aguda em transplante hepático (WAN et al., 2008).

Percebe-se portanto que um conjunto de evidências científicas apontam para uma redução da linhagem mielóide e aumento dos linfócitos TCD4 (Figura 1).

Figura 1- Ilustração representativa dos mecanismos imunomodulatórios da terapia celular com AD-MSCs na regeneração hepática. Um conjunto de evidências mostra aumento da atividade dos linfócitos Thelper (CD4) e diminuição da linhagem mielóide.

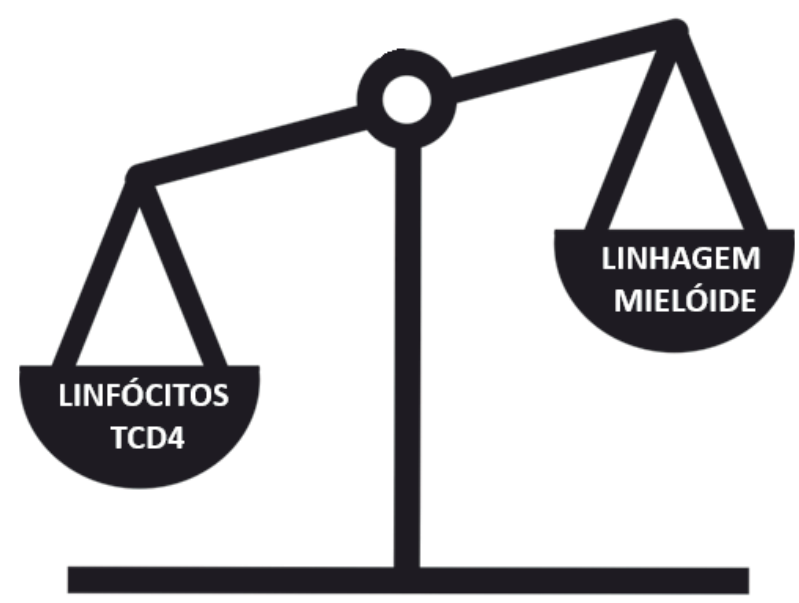

\section{Efeito antioxidante}

Estresse oxidativo tem sido relacionado com diferentes hepatopatias, como fibrose e cirrose hepáticas e hepatocarcinoma celular (TANIKAWA; TORIMURA, 2006; ZHU et al., 2012). Diferentes estudos têm demonstrado que as células tronco mesenquimais apresentam capacidade antioxidante e, desta forma, são fontes interessantes para utilização terapêutica (CHO et al., 2012; QUINTANILHA et al., 2014).

Embora pouco se saiba em relação as potencialidades das AD-MSCs em reduzir estresse oxidativo em hepatopatias, um recente estudo de 2016 utilizando um modelo de insuficiência hepática aguda, por exemplo, provou que as AD-MSCs foram capazes de aumentar a atividade do NF-E2-related fator (Nrf2), um fator de transcrição crucial na expressão de diversas enzimas relacionadas à resolução do estresse oxidativo, criando novas perspectivas para a utilização dessas células (AL-SAWAF et al., 2015; HUANG et al., 2016).

\section{CONCLUSÃO}

Apesar do grande número de publicações relacionando a terapia celular com células tronco derivadas do tecido adiposo com a resolução de doenças hepáticas, ainda não é possível determinar com precisão quais os mecanismos que medeiam este processo. Porém, um conjunto de recentes estudos compilados na tabela 1 indica que fibrinólise, imunomodulação e efeito antioxidante podem, de maneira combinada, contribuir para os bons resultados aqui apresentados (figura 2 ).

Fonte: Elaborado pelos autores

Tabela 1 - Sumário de estudos in vivo que propoem mecanismos de resolução de hepatopatias via transplante de AD-MSCs.

\begin{tabular}{|c|c|c|c|c|}
\hline Referência & País & Modelo Experimental & Métodos & Principais Resultados \\
\hline OKURA et al., 2015 & Japão & $\begin{array}{l}\text { Camundongos NUDE tratados com } \\
\text { tetracloreto de carbono }\left(\mathrm{CCl}_{4}\right) \text { por } \\
\text { seis semanas }\end{array}$ & $\begin{array}{l}\text { Infusão de } 1 \times 10^{6} / \mathrm{kg} \text { AD-MSC via veia } \\
\text { da cauda }\end{array}$ & Aumento de MMP2, MMP3 e MMP9 \\
\hline YU et al., 2013 & China & $\begin{array}{l}\text { Ratos Sprague-Dawley tratados } \\
\text { com tetracloreto de carbono }\left(\mathrm{CCl}_{4}\right) \\
\text { por quatro semanas }\end{array}$ & Infusão de $5 \times 10^{6}$ AD-MSC via portal & $\begin{array}{l}\text { Apoptose das células estreladas e me- } \\
\text { nor expressão de } \alpha \text {-SMA }\end{array}$ \\
\hline KAMADA et al., 2009 & Japão & $\begin{array}{l}\text { Camundongos } \mathrm{C} 57 \mathrm{BLI} / 6 \mathrm{~J} \text { tratados } \\
\text { com tetracloreto de carbono }\left(\mathrm{CCl}_{4}\right) \\
\text { por oito semanas }\end{array}$ & $\begin{array}{l}\text { Infusão de } 1 \times 10^{5} \text { AD-MSC GFP+ com } \\
\text { ou sem pré-tratamento com bFGF } \\
\text { via esplênica }\end{array}$ & $\begin{array}{l}\text { Aumento de metaproteinases. Níveis } \\
\text { baixos de marcadores fibrinogênicos } \\
\text { e } \alpha \text {-SMA }\end{array}$ \\
\hline $\begin{array}{l}\text { HIGASHIMOTO et al., } \\
2013\end{array}$ & Japão & $\begin{array}{l}\text { Hepatite aguda em camundon- } \\
\text { gos } \mathrm{C} 57 \mathrm{BI} / 6 \text { induzida por ConA } \\
\text { intravenoso }\end{array}$ & $\begin{array}{l}1 \times 10^{5} \text { AD-MSC administradas i.v. } \\
\text { imediatamente ou } 3 \mathrm{~h} \text { após a injeção } \\
\text { de ConA }\end{array}$ & $\begin{array}{l}\text { Diminuição de células da linhagem mie- } \\
\left.\text { lóide no fígado (CD11b } b^{+}, \mathrm{Gr}-1^{+}, \mathrm{F} 4 / 80^{+}\right)\end{array}$ \\
\hline SEKI et al., 2013 & Japão & $\begin{array}{l}\text { Esteato-hepatite não alcoólica in- } \\
\text { duzida em camundongos C57BI/6J } \\
\text { via dieta Anth1HF }\end{array}$ & $\begin{array}{l}1 \times 10^{5} \mathrm{AD}-\mathrm{MSC} \text { administradas via } \\
\text { espaço subesplênico }\end{array}$ & $\begin{array}{l}\text { Aumento da expressão de albumina e } \\
\text { diminuição da fibrose. } \\
\text { Redução do infiltrado } \mathrm{Gr}-1^{+}, \mathrm{CD} 11 \mathrm{~b}^{+} \mathrm{e} \\
\text { da relação } \mathrm{CD} 8^{+} / \mathrm{CD} 4^{+}\end{array}$ \\
\hline WAN et al., 2008 & China & $\begin{array}{l}\text { Transplante hepático ortópico } \\
\text { entre ratos Sprague-Dawley (reci- } \\
\text { piente) e Wistar (doador) }\end{array}$ & $\begin{array}{l}\text { AD-MSC foram utilizadas no modelo } \\
\text { de transplante. }\end{array}$ & $\begin{array}{l}\text { Redução de ALT, AST, bilirrubina, IL-2 e } \\
\text { aumento de IL-10. Redução das taxas } \\
\text { de apoptose dos hepatócitos. }\end{array}$ \\
\hline HUANG et al., 2016 & China & $\begin{array}{l}\text { Ratos } \mathrm{C} 57 \mathrm{BL} / 6 \text { tratados com aceta- } \\
\text { minofeno por oito semanas }\end{array}$ & $\begin{array}{l}\text { Infusão de } 1 \times 10^{6} \text { AD-MSC via veia } \\
\text { da cauda }\end{array}$ & Aumenta a atividade de Nrf2 \\
\hline
\end{tabular}

Fonte: Elaborada pelos autores 
Figura 2 - Esquema dos principais mecanismos propostos envolvidos na regeneração hepática com a utilização da terapia celular com AD-MSCs.

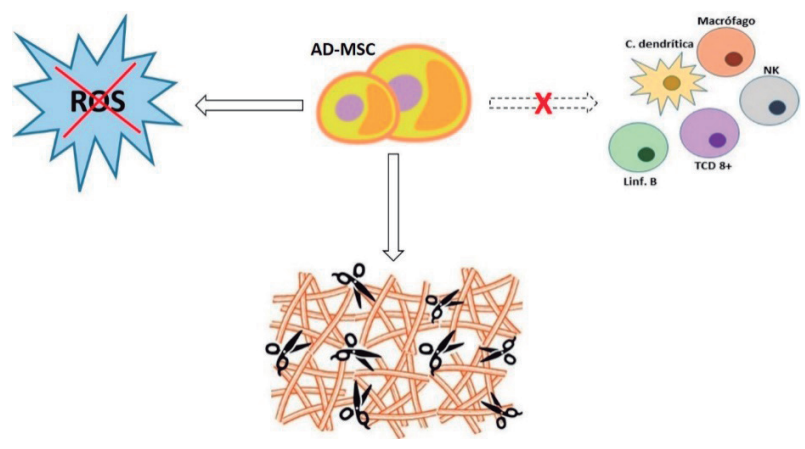

Fonte: Elaborada pelos autores

\section{REFERÊNCIAS}

AL-SAWAF, O. et al. Nrf2 in health and disease: current and future clinical implications. Clin. sci, Oxford, v. 129, n. 12, p. 989-999, Sept. 2015.

ANDREONE, P. et al. Reinfusion of highly purified CD133+ bone marrow-derived stem/progenitor cells in patients with end-stage liver disease: a phase I clinical trial. Dig. liver dis., Roma, v. 47, n. 12, p. 1059-1066, Dec. 2015.

BARROS, M. B. de A. et al. Tendências das desigualdades sociais e demográficas na prevalência de doenças crônicas no Brasil, PNAD: 2003- 2008. Ciênc. saúde coletiva, Rio de Janeiro, v. 16, n. 9, p. 3755-3768, set. 2011.

$\mathrm{CHO}$, K. et al. Mesenchymal stem cells restore $\mathrm{CCl}_{4}$-induced liver injury by an antioxidative process. Cell biol. int., London, v. 36, n. 12, p. 12671274, Dec. 2012.

CROP, M. J. et al. Inflammatory conditions affect gene expression and function of human adipose tissue-derived mesenchymal stem cells. Clin. exp. immunol., v. 162, n. 3, p. 474-486, Dec. 2010a.

CROP, M. J. et al. Human adipose tissue-derived mesenchymal stem cells induce explosive t-cell proliferation. Stem cells dev., Larchmont, v. 19, n. 12, p. 1843-1853, Dec. 2010b.

D'AMICO, G. et al. Natural history and prognostic indicators of survival in cirrhosis: a systematic review of 118 studies. J. hepatol., Amsterdam, v. 44, n. 1, p. 217-231, Jan. 2006.

FATHI, E.; FARAHZADI, R. Isolation , culturing , characterization and aging of adipose tissue-derived mesenchymal stem cells : a brief overview. Braz. arch. biol. technol., Curitiba, v. 59, p. 1-9, Dec. 2016.

HALDAR, D. et al. Mesenchymal stromal cells and liver fibrosis: a complicated relationship. Faseb J., Bethesda, 2016.

HEIDARI, B. et al. Comparison of proliferative and multilineage differentiation potential of sheep mesenchymal stem cells derived from bone marrow, liver, and adipose tissue. Avicenna j. med. biotechnol., Bethesda, v. 5, n. 2, p. 104-117, Apr. 2013.

HIGASHIMOTO, M. et al. Adipose tissue derived stromal stem cell therapy in murine ConA-derived hepatitis is dependent on myeloid-lineage and CD4 ${ }^{+}$T-cell suppression. Eur. j. immunol., Weinheim, v. 43, n. 11, p. 2956-2968, Nov. 2013.

HUANG, Y.J. et al. Protection against acetaminophen-induced acute liver failure by omentum adipose tissue derived stem cells through the mediation of Nrf2 and cytochrome P450 expression. J. biomed. sci., Basel, v. 23, n. 1, p. 5, Dec. 2016.
ISHIKAWA, T. et al. Fibroblast growth factor 2 facilitates the differentiation of transplanted bone marrow cells into hepatocytes. Cell tissue res., Berlin, v. 323, n. 2, p. 221-231, 14 Feb. 2006.

ISHIKAWA, T. et al. Stem cells for hepatic regeneration : the role of adipose tissue derived mesenchymal stem cells. Curr. Stem Cell Res. Ther.,[S.I], v. 2511, n. 4800, p. 182-189, 2010.

JORNS, C. et al. Hepatocyte transplantation for inherited metabolic diseases of the liver. J. intern. med., Oxford,v. 272, n. 3, p. 201-223, Sept. 2012.

KAMADA, Y. et al. Transplantation of basic fibroblast growth factor-pretreated adipose tissue-derived stromal cells enhances regression of liver fibrosis in mice 2. Am. J. Physiol. Gastrointest. Liver Physiol., Bethesda, v. 296, n. 0193-1857 (Print), p. G157-G167, 2009.

KIM, W.H. et al. Growth inhibition and apoptosis in liver myofibroblasts promoted by hepatocyte growth factor leads to resolution from liver cirrhosis. Am j. clin. pathol., Philadelphia, v. 166, n. 4, p. 1017-1028, Apr. 2005.

LIANG, L. et al. Therapeutic potential and related signal pathway of adipose-derived stem cell transplantation for rat liver injury. Hepatol. res., Amsterdam, v. 39, n. 8, p. 822-832, Ago. 2009.

MOHAMADNEJAD, M. et al. Intraportal Infusion of bone marrow mononuclear or cd133+ cells in patients with decompensated cirrhosis: a double-blind randomized controlled trial. Stem cells transl. med., Bethesda, v. 5, n. 1, p. 87-94, Jan. 2016.

OKURA, H. et al. Therapeutic potential of human adipose tissue-derived multi-lineage progenitor cells in liver fibrosis. Biochem. biophys. res. commun., New York, v. 456, n. 4, p. 860-865, 2015.

QUINTANILHA, L. F. et al. Canine mesenchymal stem cells show antioxidant properties against thioacetamide-induced liver injury in vitro and in vivo. Hepatol. res., Amsterdam,v. 44, n. 10, p. E206-E217,Oct. 2014.

SEKI, A. et al. Adipose tissue-derived stem cells as a regenerative therapy for a mouse steatohepatitis-induced cirrhosis model. Hepatology, Baltimore, v. 58, n. 3, p. 1133-1142, 2013.

SHIRATSUKI, S. et al. Enhanced survival of mice infused with bone marrow-derived as compared with adipose-derived mesenchymal stem cells. Hepatol. res., Amsterdam, v. 45, n. 13, p. 1353-1359, Dec. 2015.

TANIKAWA, K.; TORIMURA, T. Studies on oxidative stress in liver diseases: important future trends in liver research. Med. Mol. Morphol., Tokyo, v. 39, n. 1, p. 22-27, Mar. 2006.

VOLAREVIC, V. et al. Concise review: therapeutic potential of mesenchymal stem cells for the treatment of acute liver failure and cirrhosis. Stem Cells, Basel, p. 2818-2823, 2014.

WAN, C.D. et al. Immunomodulatory effects of mesenchymal stem cells derived from adipose tissues in a rat orthotopic liver transplantation model. Hepatobiliary pancreat. dis. int., China, v. 7, n. 1, p. 29-33, Feb. 2008.

WP, T. FGF-treated adipose tissue-derived mesenchymal stem cell infusion ameliorate liver cirrhosis via paracrine HGF. J. gastroenterol. hepatol., Melbourne, v. 30, n. 6, p. 1-31, 2015.

YARAK, S. Células-tronco derivadas de tecido adiposo humano: desafios atuais e perspectivas clínicas * 647 . An. bras. dermatol., Rio de Janeiro, v. 85, n. 5, p. 647-656, 2010.

YIN, L. et al. Adipose tissue-derived mesenchymal stem cells differentiated into hepatocyte-like cells in vivo and in vitro. Mol Med Rep., Greece, v.11, n. 3, Nov. 2014.

YU, F. et al. Adipose-derived mesenchymal stem cells inhibit activation of hepatic stellate cells in vitro and ameliorate rat liver fibrosis in vivo. J. Formos. Med. Assoc., Taipei, p. 1-9, 2013. 
ZHANG, Z. et al. Stem cell therapies for liver failure and cirrhosis. J. hepatol., Amsterdam, v. 59, n. 1, p. 183-185, July 2013.

ZHU, R. et al. Oxidative stress and liver disease. Hepatol. res., Amster- dam, v. 42, n. 8, p. 741-749, Ago. 2012.

ZUK, P. A. The adipose-derived stem cell: looking back and looking ahead. Mol. biol. cell, Bethesda, v. 21, n. 11, p. 1783-1787, June 2010.

Submetido em: 07/06/2017

Aceito em: 14/07/2017 